\title{
Convivendo com o Câmbio Flutuante
}

\author{
Living with a Floating Exchange Rate
}

\author{
MARYSE FARH* \\ MARCOS ANTONIO MACEDO CINTRA**
}

\begin{abstract}
RESUMO: Desde a implementação de um sistema de câmbio flutuante pelas autoridades econômicas brasileiras em meados de 1999, a trajetória da taxa de câmbio real tem sido caracterizada por extrema volatilidade, inerente a esse sistema. O mercado financeiro brasileiro, no entanto, tem a vantagem de possuir um mercado de derivativos razoavelmente líquido que pode contribuir para um 'relacionamento' menos turbulento com um regime de câmbio flutuante. No entanto, quaisquer possíveis benefícios desse mercado para a economia brasileira exigiriam: o uso rotineiro de derivativos financeiros por agentes econômicos em sua gestão de negócios, a eliminação de qualquer restrição ao acesso a mercados de derivativos por investidores estrangeiros e o aprimoramento dos procedimentos de supervisão e regulamentação. mecanismos.
\end{abstract}

PALAVRAS-CHAVE: Regime cambial; taxa de câmbio; câmbio flutuante; estabilização; regulação.

ABSTRACT: Since the implementation of a floating exchange system by the Brazilian economic authorities in mid-1999, the trajectory of the real exchange rate has been characterized by extreme volatility, inherent in such a system. The Brazilian financial market, however, has the advantage to possess a reasonably liquid derivative market which can contribute to a less turbulent 'relationship' with a floating exchange regime. Nevertheless, any possible benefits from this market to the Brazilian economy would require: the routine use of financial derivatives by economic agents in their business management, the elimination of any restriction to access to derivative markets by foreign investors, and the improvement of supervisory and regulatory mechanisms.

KEYWORDS: Exchange rate regime; exchange rate; floating exchange rate; stabilization; regulation.

JEL Classification: E42; E58; F31.

\footnotetext{
* Doutora pelo Instituto de Economia da Unicamp, atualmente desenvolve projeto de pesquisa na Diretoria de Economia do Setor Público da Fundap, com bolsa de pós-doutoramento da Fapesp. São Paulo/SP, Brasil. e-mail: maryze.fahri@gmail.com.

* Doutor pelo Instituto de Economia da Unicamp, pesquisador da Diretoria de Economia do Setor Público da Fundap e professor da Universidade lbirapuera, São Paulo/SP, Brasil. E-mail: mamcintra@ gmail.com.
} 
A extrema volatilidade e acentuada elevação das incertezas dos agentes econômicos caracterizam o período posterior à instauração do regime de taxa de câmbio flutuante no Brasil. A trajetória da taxa de câmbio desde a mudança do regime cambial pode ser decomposta em quatro fases. $\mathrm{Na}$ primeira, de meados de janeiro ao início de março de 1999, ocorreu uma desvalorização cambial descontrolada, em que a cotação do dólar atingiu $\mathrm{R}$ \$2,20. A exacerbação das incertezas e operações especulativas ligadas ao vencimento do mercado futuro de câmbio provocaram um movimento próximo ao pânico em 29 de janeiro, apenas 15 dias após a tomada de decisão do governo. Na segunda, entre março e meados de maio, houve uma forte valorização do real, que chegou a R \$1,65/dólar na primeira quinzena de maio, em parte devido às intervenções do Banco Central. $\mathrm{Na}$ terceira, de meados de maio ao final de outubro, aconteceu uma segunda onda de desvalorização cambial, com o dólar atingindo em outubro a sua cotação média mensal mais elevada do ano ( R \$ 1,97), dada a concentração de compromissos externos e a persistência dos déficits comerciais. Na quarta, do final de outubro até dezembro, houve nova valorização do real, com o dólar atingindo $\mathrm{R}$ \$1,79 e o Banco Central recuperando sua capacidade de intervenção após a renegociação com o Fundo Monetário Internacional (FMI) do nível mínimo de reservas internacionais líquidas (descontandose os recursos provenientes do acordo com o FMI e o Banco para Compensações Internacionais).

Parece razoável supor que, após as exageradas reações iniciais, a taxa de câmbio do real poderia aproximar-se de um valor definido como de equilíbrio, como apregoam as autoridades ${ }^{1}$ Contudo, a experiência internacional mostra que num sistema de câmbio flutuante, tal valor de equilíbrio é instável e sujeito não somente às mudanças nas condições macroeconômicas, mas igualmente às alterações de expectativas (Goldstein, Folkerts-Landau, et alii, 1993). Nesse sentido, a variação entre o dólar e o iene alcançou $65 \%$ entre janeiro de 1995 e setembro de 1998 . No Brasil, a volatilidade das taxas de câmbio está sendo muito superior àquela verificada com a política das minidesvalorizações antes do Plano Real ou com a banda de flutuação implementada em 1995, mesmo com intervenções (pontuais e imprevisíveis ou seguindo determinadas regras conhecidas) do Banco Central para atenuar sua amplitude.

A ruptura do acordo de Bretton Woods, no início da década de 70, levou à adoção do sistema de taxas de câmbio flutuantes entre as moedas dos principais países desenvolvidos. A instabilidade dos principais parâmetros financeiros (taxa de câmbio e de juro) teve enormes repercussões no comportamento dos agentes econômicos. A ausência de elementos de cálculo econômico e a indefinição dos preços relativos e absolutos, seja das matérias-primas, dos produtos finais, ou dos ativos financeiros, levaram os agentes econômicos a embutir em seus preços um componente de defesa contra a volatilidade (mark up). Isso resultou em um pro-

\footnotetext{
${ }^{1}$ Em entrevista, no início do ano 2000, o presidente Fernando Henrique Cardoso sugeriu que o valor de equilíbrio da taxa de câmbio do real situar-se-ia entre $\mathrm{R}$ \$1,75 e R \$ 1,85 por dólar.
} 
cesso de inflação combinado com desaceleração da taxa de crescimento econômico, conhecido como estagflação (Tavares \& Belluzzo, 1986). A busca de proteção contra esse ambiente financeiro instável esteve na base da introdução e do acentuado crescimento dos mercados de derivativos financeiros.

A ampla utilização de instrumentos derivativos para a cobertura dos riscos cambiais dos agentes vem limitando o impacto das flutuações das taxas de câmbio no lado real das principais economias industrializadas (Farhi, 1998 e 1999). Variações relativamente amplas nas relações entre o dólar americano, o iene japonês e as diversas moedas europeias ou, mais recentemente, o euro, são frequentes e não provocam bruscas elevações de preços ou incapacidade de firmar contratos para liquidação futura em divisas (Boissieu \& Aglietta, 1994).

Esse papel estabilizador dos mercados de derivativos financeiros é contrabalançado pelo fato de que seus mecanismos inerentes os tornam instrumentos privilegiados de especulação devido a seu alto poder de alavancagem. Embora os especuladores forneçam a liquidez necessária para a realização das operações de cobertura de riscos, sua atuação pode vir a tornar as crises mais agudas. Entretanto, nas características atuais das finanças internacionais, em que trilhões de dólares circulam, em questões de segundos, de um país a outro, provocando uma elevada volatilidade nas taxas de câmbio (e, por consequência, nas taxas de juros), torna-se essencial a existência de mecanismos que permitam a fixação, no presente, dos custos futuros das operações comerciais, industriais ou financeiras (Bourguinat, 1995). A adoção de um regime de flutuação da taxa de câmbio, já considerada penosa nos países desenvolvidos, é ainda mais árdua naqueles como o Brasil, o México ou os asiáticos, dados os desequilíbrios e as distorções de suas economias (ver tabela 1$)^{2}$. Em relação a esses países, o Brasil tem a considerável vantagem de possuir um mercado de derivativos constituído e razoavelmente líquido, o que pode permitir uma convivência menos turbulenta com o sistema de câmbio flutuante.

Porém, para que a economia brasileira obtenha os possíveis benefícios desses mercados, será necessário superar diversos obstáculos, de naturezas variadas. A utilização dos instrumentos derivativos permanece restrita a um pequeno número de agentes altamente sofisticados, tais como instituições financeiras e grandes empresas. Torna-se necessário uma disseminação do conhecimento dos mecanismos de operação e das formas de utilização desses instrumentos de cobertura de riscos para limitar os efeitos disruptivos que as incertezas cambiais podem introduzir no sistema econômico. Além disso, os principais agentes econômicos precisam empregar esses instrumentos de forma rotineira na gestão dos seus negócios e não apenas como mecanismos especulativos ou como cobertura de risco nos momentos em que se esperam grandes alterações na conjuntura macroeconômica e em que se busca no Banco Central a principal fonte de hedge ${ }^{3}$.

\footnotetext{
${ }^{2}$ Ver Miranda (1998) e Kregel (1998). Ver, também, Relatório da Secretaria de Política Econômica do Ministério da Fazenda, “Seção Especial — V”, Brasília, D.F., 1999 (http://www.fazenda.gov.br).

${ }^{3}$ Após a mudança na política cambial e a retirada do Banco Central do mercado de futuros, o volume
} 
Faz-se mister também a não-restrição de acesso dos investidores estrangeiros ao mercado de derivativos financeiros no Brasil. ${ }^{4} \mathrm{O}$ governo brasileiro já havia eliminado grande parte das restrições existentes ao capital estrangeiro, com exceção da proibição de se realizarem operações de derivativos financeiros no mercado interno, adotada em meados de 1995. Apenas os investidores do Anexo IV, cujos recursos são exclusivamente destinados ao mercado de ações, podem utilizar os derivativos exclusivamente para cobertura dos riscos inerentes a esse mercado. Isso baseia-se em um temor em oferecer armas suplementares aos especuladores, uma vez que os derivativos lhes permitiriam especular mais facilmente contra a moeda brasileira devido ao elevado grau de alavancagem. ${ }^{5}$ Especulação essa que o Banco Central, antes da mudança de política cambial, estava procurando combater mediante a venda de títulos da dívida pública doméstica com correção cambial e contratos de câmbio no mercado futuro, além da elevação da taxa de juros.

Tabela 1: Desvalorização cambial, inflação e PIB após crise cambial

\begin{tabular}{lccccccccc}
\hline & $\begin{array}{c}\text { Coréia } \\
\text { do Sul }\end{array}$ & Tailândia & México & Brasil & & & & \\
\hline & $\begin{array}{c}1 \text { ano } \\
\text { depois }\end{array}$ & $\begin{array}{c}2 \text { anos } \\
\text { depois }\end{array}$ & $\begin{array}{c}1 \text { ano } \\
\text { depois }\end{array}$ & $\begin{array}{c}2 \text { anos } \\
\text { depois }\end{array}$ & $\begin{array}{c}1 \text { ano } \\
\text { depois }\end{array}$ & $\begin{array}{c}2 \text { anos } \\
\text { depois }\end{array}$ & $\begin{array}{c}1 \text { ano } \\
\text { depois }\end{array}$ & $\begin{array}{c}2 \text { anos } \\
\text { depois }\end{array}$ \\
\hline $\begin{array}{c}\text { Desvalorização } \\
\text { Cambial (\%) }\end{array}$ & 48 & 31 & 73 & 55 & 123 & 126 & 58 & 54 \\
$\begin{array}{c}\text { Inflação } \\
\text { Acumulada (1) }\end{array}$ & 7 & 8 & 10 & 9 & 52 & 94 & 9 & 17 \\
$\begin{array}{c}\text { Coeficiente de } \\
\text { Repasse da Inflação }\end{array}$ & 14 & 25 & 14 & 16 & 42 & 75 & 15 & 31 \\
PIB (variação\%) & $-5,8$ (2) & 9,0 (3) (a) & $-8,0$ (2) & 3,8 (3)(a) & $-6,2$ (4) & 5,2 (5) & 0,7 (3)(a) & 3,0 (6)(a) \\
\hline
\end{tabular}

Fonte: Silveira (1999: p. 17) a partir de dados do FMI e revista The Economist.

Notas: (1) Preços ao consumidor, (2) Crescimento do PIB em 1998; (3) Crescimento do PIB em 1999; (4) Crescimento do PIB em 1995; (5) Crescimento do PIB em 1999; (6) Crescimento do PIB em 2000; (a) Estimativa.

negociado de derivativos de câmbio sofreu queda significativa. A média diária de giros dos contratos de câmbio futuro caiu 72,36\% em abril de 1999 em relação ao mesmo período de 1998, e 45,28\% em relação a janeiro de 1999 (Lucchesi, 1999a). O volume financeiro médio diário negociado na Bolsa Mercantil \& Futuros (BM\&F) reduziu-se de US\$ 23,8 bilhões em 1998 para US\$ 9,7 bilhões em 1999, registrando uma queda de 59\% (Silva, 2000 ). Ver também Bolsa Mercantil \& Futuros (1999).

${ }^{4}$ Quando investidores estrangeiros decidem aplicar seus recursos em economias emergentes, como o Brasil, sua demanda por derivativos financeiros, notadamente os que têm a taxa de câmbio com ativo subjacente, é bastante elevada. Mediante a utilização de derivativos, dirigem-se para as Bolsas de Valores, ao mercado de ativos reais, ou procuram usufruir do mercado de renda fixa (sobretudo, títulos da dívida pública com elevada taxa de juros) sem correr riscos cambiais. Foi por essa razão que, por exemplo, as opções cambiais negociadas na BM\&F experimentaram um salto fantástico a partir de 1993, com o número de contratos em aberto crescendo cerca de $800 \%$.

${ }^{5}$ Sobre os graus de alavancagem permitidos pelos instrumentos derivativos, ver President's Working Group..., 1999. 
É sabido que a proibição aos investidores estrangeiros de atuar nos mercados de derivativos financeiros brasileiros direcionou essa demanda para o exterior. Passou-se a negociar, sobretudo nos Estados Unidos e na Inglaterra, derivativos com ativos brasileiros como subjacentes. Embora a maior parte desses derivativos tenha a taxa de câmbio do real como ativo subjacente, registra-se também um bom volume de negócios com derivativos sobre títulos da dívida externa e índices de Bolsas de Valores. Foram igualmente criados derivativos com ativos subjacentes mais "exóticos", como o risco de moratória (swap ou opções de default). Em setembro de 1998, quando da crise russa, esse mercado alcançava US\$ 10 bilhões em valor nocional. O essencial das negociações desses derivativos ocorre nos mercados de balcão, com exceção do contrato futuro da taxa de câmbio do real em dólar americano negociado na Bolsa de Chicago. ${ }^{6}$ Curiosamente, foi nesse mercado que surgiu a primeira indicação de que o governo brasileiro deixaria a taxa de câmbio flutuar. Na véspera do anúncio dessa decisão, o real já estava sendo negociado em Chicago acima da banda fixada pelo Banco Central do Brasil.

Assim, a simples existência de mercados de derivativos com ativos brasileiros como subjacentes no exterior torna a precaução governamental desnecessária, visto que um ataque especulativo pode ser montado em Chicago, Londres ou alhures. Nesse sentido, Lucchesi (19996) informa que os "contratos de derivativos financeiros deverão ser li berados para negociação por agentes não residentes até junho de 2000" pelo Banco Central. Acreditamos que trazer para o mercado doméstico as operações dos capitais estrangeiros em derivativos sobre ativos brasileiros permitiria a constituição de um mercado mais amplo, mais líquido e mais transparente, reduzindo as possibilidades de manipulação e aumentando a disposição dos diferentes agentes em utilizá-lo para a cobertura de seus riscos.

Para que esse mercado funcione sem sobressaltos, seria necessário ainda um aperfeiçoamento dos mecanismos de supervisão e regulamentação. O mercado de derivativos é extremamente dinâmico e inovador e os mecanismos prudenciais, geralmente, são implementad os de forma ex post. Porém, o fosso entre as inovações financeiras e a supervisão das autoridades não deve se alargar em demasia. A Comissão Parlamentar de Inquérito dos Bancos (1999) teve o mérito de mostrar que muito ainda precisa ser realzado nesse campo, como, por exemplo, atribuir a um único organismo a jurisdição de supervisão, atualmente compartilhada pela Comissão de Valores Mobiliários (CVM) e pelo Banco Central. No que concerne especificamente às instituições financeiras, o Banco Central deveria avançar na implementação do controle dos graus de alavancagem das carteiras das instituições financeiras e/ou dos fundos por elas administrados, do netting ${ }^{7}$ e da análise da

\footnotetext{
${ }^{6}$ Os mercados de balcão são bastante opacos, sendo difícil determinar os níveis de preços, os maiores participantes, os volumes negociados etc. Porém, mesmo no caso do mercado futuro de taxa de câmbio do real em Chicago, a informação disponível no Brasil permanece restrita aos sistemas on-line, não sendo publicada nos jornais de negócios.

${ }^{7} \mathrm{O}$ netting consiste na compensação dos créditos e débitos recíprocos pelo saldo líquido a receber o u a pagar, reduzindo o risco de crédito em caso de inadimplência de uma das partes.
} 
sensibilidade dos modelos de avaliação de risco contemplados no Acordo de Basiléia. No que se refere à auto-regulamentação, defendida em escala internacional pelos grandes bancos americanos e pelo governo dos Estados Unidos, a questão deveria ser tratada com mais rigor pelas bolsas de valores e de derivativos, bem como pelas associações de corretoras e de bancos, de forma a elevar a segurança e a transparência das operações.

Enfim, argumentamos que a perpetuação no tempo do regime de taxas de câmbio flutuante impõe a generalização do uso dos inst rumentos de derivativos financeiros para devolver aos agentes internos e externos a previsibilidade das taxas de câmbio e, portanto, dos diferentes preços e das decisões de produção, de investimento e de alocação dos portfólios financeiros.

\section{REFERÊNCIAS BIBLIOGRÁFICAS}

BOISSIEU, C. \& AGLIEITA, M. (1994) “Les marchés dérivés de gré à gré et le risque systémique”. Bulletin COB, No, 283, Paris.

BOLSA MERCANTIL \& FUTUROS (1999) Impacto da alteração da política cambial nos mercados da $B M \& F$. São Paulo: BM\&F (http://www.bjf.com.br/papers/publicacoes1/impactoalteracao).

BOURGUINAT, Henri (1995) La tyrannie des marchés. Essai sur l'économie virtuelle. Paris: Economica.

COMISSÃO Parlamentar de Inquérito dos Bancos (1999) Relatório final. Brasília, D.F.: Senado Federal (Requerimento No. 127).

FARHI, Maryse (1998) O futuro no presente: um estudo dos mercados de derivativos financeiros. Campinas: Instituto de Economia/Unicamp (Tese de Doutoramento).

FARHI, Maryse (1999) "Hedge, especulação e arbitragem". Revista Economia e Sociedade, No. 13. Campinas: Instituto de Economia/Unicamp, p. 93-114.

GOLDSTEIN, Morris; FOLKERTS-LANDAU, David et alii (1993) International capital markets: Part 1. Exchange rate management and international capital flows. Washington, DC: International Monetary Fund (World Economic and Financial Surveys).

KREGEL, J. A. (1998) "Derivatives and global capital flows: applications to Asia". Working Paper, No. 246. N.Y.: The Jeromy Levy Economics Institute.

LUCCHESI, Cristiane Perini (1999a) "Negócios com dólar comercial futuro despencam na BM\&F", Gazeta Mercantil, São Paulo, 3 de maio, p. B-1.

LUCCHESI, Cristiane Perini (1999b) "BM\&F reestrutura-se para retomar espaço perdido", Gazeta Mercantil , São Paulo, 27 de dezembro, p. B-4.

MIRANDA, José Carlos (1998) "A dinâmica financeira da crise asiática”, Revista Política Externa, Vol. 6, No. 4. São Paulo: Ed. Paz e Terra/USP-Política Internacional Comparada, p. 130-150.

SILVA, Altair (2000) "BM\& F espera maior demanda por hedge", Gazeta Mercantil, São Paulo, 13 de janeiro, p. B-3.

SILVEIRA, Caio César Lock Prates da (1999) "Panorama Geral”, Boletim de Conjuntura, Vol. 19, No, 4. Rio de Janeiro: Instituto de Economia/UFRJ.

PRESIDENT'S Working Group on Financial Markets (1999) Hedge funds, leverage, and the lessons of Long-Term Capital Management. Washington, D.C.

TAVARES, Maria da Conceição \& BELLUZZO, Luiz Gonzaga de Mello (1986) "Uma reflexão sobre a natureza da inflação contemporânea”, in: REGO, José Márcio (Org.) Inflação inercial, teorias sobre inflação e o Plano Cruzado. Rio de Janeiro: Ed. Paz e Terra. 